
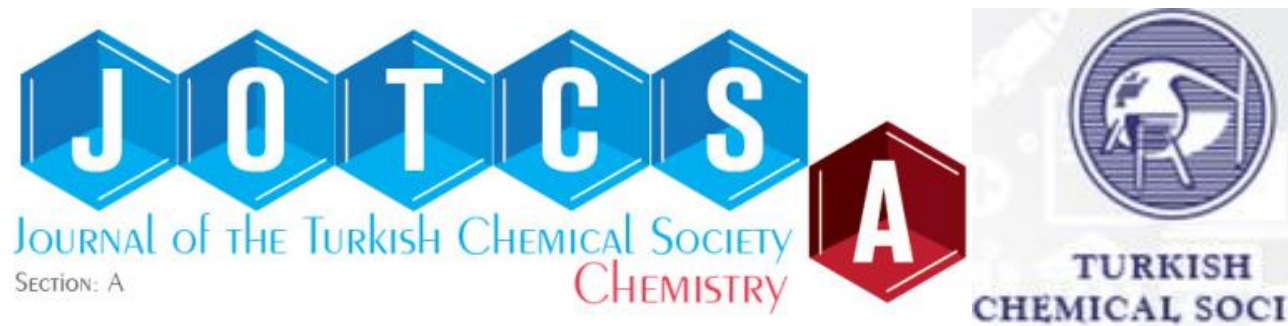

TURKISH

CHEMICAL SOCIETY

\title{
Adsorption of Metamizole Sodium by Activated Carbon in Simulated Gastric and Intestinal Fluids
}

\section{Elif ÇALIŞKAN SALİH'̈ ${ }^{1 *}$}

${ }^{1}$ Marmara University, Faculty of Pharmacy, Department of Basic Pharmaceutical Sciences, 34668, Haydarpasa, Istanbul, Turkey

Abstract: In vitro adsorption of metamizole sodium by activated carbon was studied at $\mathrm{pH} 1.2$ and 7.5 in order to simulate gastric and intestinal fluids. In the first 5 minutes, more than eighty percent of the total adsorption occurred but the adsorption process achieved to the equilibrium in 1 hour. Time to reach equilibrium did not change with the changing $\mathrm{pH}$, concentration of the adsorbate or the adsorbent amount. The equilibrium data followed the Langmuir model and therefore fitted to L-type in accordance with the Giles classification for adsorption isotherms. The maximum removal capacities of the activated carbon for metamizole sodium were calculated using Langmuir equation and found as $185.19 \mathrm{mg} / \mathrm{g}$ and $161.29 \mathrm{mg} / \mathrm{g}$ at $\mathrm{pH} 1.2$ and 7.5, respectively.

Keywords: Adsorption, Metamizole sodium, Gastric fluid, Intestinal fluid, Dipyrone.

Submitted: November 15, 2017. Accepted: December 24, 2017.

Cite this: Çalışkan Salihi E. Adsorption of Metamizole Sodium by Activated Carbon in Simulated Gastric and Intestinal Fluids. JOTCSA. 2018;5(1):237-46.

DOI: http://dx.doi.org/10.18596/jotcsa.353590.

*Corresponding author. E-mail: caliskanelif@gmail.com. 


\section{INTRODUCTION}

Metamizole sodium (MS), also known as dipyrone, is a pyrazolone derivative and represents analgesic and antipyretic activity. The molecular structure of MS is shown in Figure 1. It was withdrawn already in several countries due to its potentially fatal adverse effects. The most serious adverse effect of MS is agranulocytosis. Studies showed that MS overdose usually causes mild toxicity and occurs mainly at home by the oral route and in relation to a considerable number of suicide attempts. However, MS is still widely used as an over the counter preparation in adults and children in many countries (1). The use of MS during pregnancy and postpartum even exceeds the use of paracetamol in some of these countries. Studies report that metabolites of MS were found in the breast milk in concentrations similar to those in the maternal serum (2).

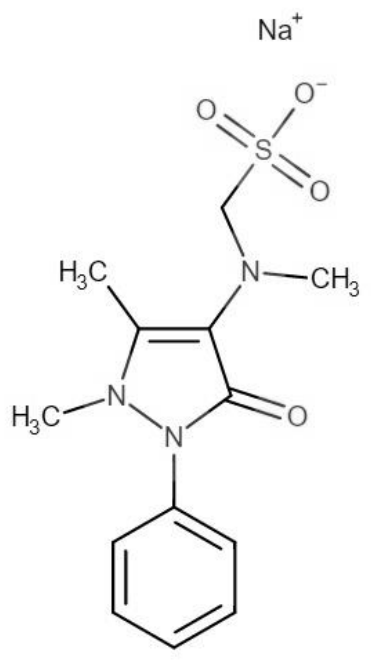

Figure 1: Chemical structure of MS (metamizole sodium).

Drug poisoning is a common and serious clinical problem. Because many drugs used do not have any specific antidote for the treatment of poisoning. If the specific antidote does not exist, gastrointestinal adsorbents are beneficial for the treatment of overdose or poisoning by preventing the further absorption of drug. Activated carbon is widely used as a gastrointestinal adsorbent and has been successfully applied in the cases of overdosing of many pharmaceuticals (3). Activated carbons are also commonly used in the industries relevant to water treatment, pharmaceutical and food as adsorbent materials due to their highly porous structure and large adsorption capacity. However, there are limited number of studies investigating the adsorption rate and capacity of activated carbon for a certain drug including the effect of $\mathrm{pH}$ on the adsorption (4-12). Nabais et al. have studied the adsorption of fluoxetine in activated carbons and activated carbon fibers at gastric and intestinal $\mathrm{pH}$ values and reported most of the materials tested have potential for treating potential fluoxetine intoxications (13). 
In the literature, there was no study on the adsorption of MS on activated carbon or any other adsorbent. So, the objective of the current study was to explore the in vitro adsorption of metamizole sodium using commercial powder activated carbon in the simulated gastric and intestinal fluids. Adsorption studies were conducted at $37^{\circ} \mathrm{C}$ (body temperature) using various contact times, adsorbent amounts and initial adsorbate concentrations. Data from the equilibrium studies were modeled by using Langmuir and Freundlich isotherm equations and adsorption capacities were calculated.

\section{MATERIALS AND METHODS}

Powdered activated carbon (PAC) was obtained from Merck. Surface and textural characterization of PAC used have been described in detail elsewhere (4). Briefly, the surface area and pHPZC (PZC: point of zero charge) of PAC are $780 \mathrm{~m}^{2} / \mathrm{g}$ and 9.5, respectively. MS was supplied by Sigma ( $\geq 98 \%)$.

The adsorption experiments were conducted in simulated gastric fluid (SGF) and simulated intestinal fluid (SIF). Stock solutions of MS were prepared in SGF $(\mathrm{pH}=1.2)$ which contains $\mathrm{NaCl}$ and concentrated $\mathrm{HCl}$ (pepsin omitted) and SIF $(\mathrm{pH}=7.5)$ which contains $\mathrm{NaH}_{2} \mathrm{PO}_{4}$ and $\mathrm{NaOH}$ (without pancreatin). All the solutions were prepared by using purified (MilliQ) water and used at once. $100 \mathrm{~mL}$ of MS solutions of a known concentration (10 to $100 \mathrm{mg} / \mathrm{L}$ ) were shaken with PAC (25 to $250 \mathrm{mg}$ ) in glass containers at $37^{\circ} \mathrm{C}$ for 1 hour using a thermostatic shaker with a water bath. Separation of the samples was done with microfilters $(0.45 \mu \mathrm{m})$. Concentrations of MS in the samples were measured with a spectrophotometer (Shimadzu, UVvisible) at $225 \mathrm{~nm}$. Concentrations of the samples were calculated using calibration curves prepared for MS. The same arrangement were used also for the kinetic experiments. Blank experiments (without adsorbent) were performed and all the experiments were repeated at least three times under identical conditions.

\section{RESULTS AND DISCUSSION}

In vitro adsorption of MS was performed in both SGF and SIF. In order to find the time to reach equilibrium, adsorption experiments were carried out using various shaking times. In the first 5 minutes, more than eighty percent of the total adsorption occurred but the adsorption process achieved to the equilibrium in 1 hour (Figure 2). The time to reach equilibrium did not change with changing $\mathrm{pH}$, adsorbate concentration and the amount of adsorbent. So the adsorption of MS was carried out using 1 hour as shaking time at body temperature, $37{ }^{\circ} \mathrm{C}$. The amount of adsorption $(\mathrm{q}, \mathrm{mg} / \mathrm{g}$ ) was calculated as given below: 


$$
q=\frac{\left(C_{0}-C_{t}\right) V}{w}
$$

$\mathrm{C}_{0}$ shows the initial concentration of $\mathrm{MS}(\mathrm{mg} / \mathrm{L})$ and $\mathrm{C}_{\mathrm{t}}$ shows the concentration of $\mathrm{MS}(\mathrm{mg} / \mathrm{L})$ at any time $(t) . V$ is the volume of MS solution used $(L)$ and $w$ is the mass of PAC $(g)$.

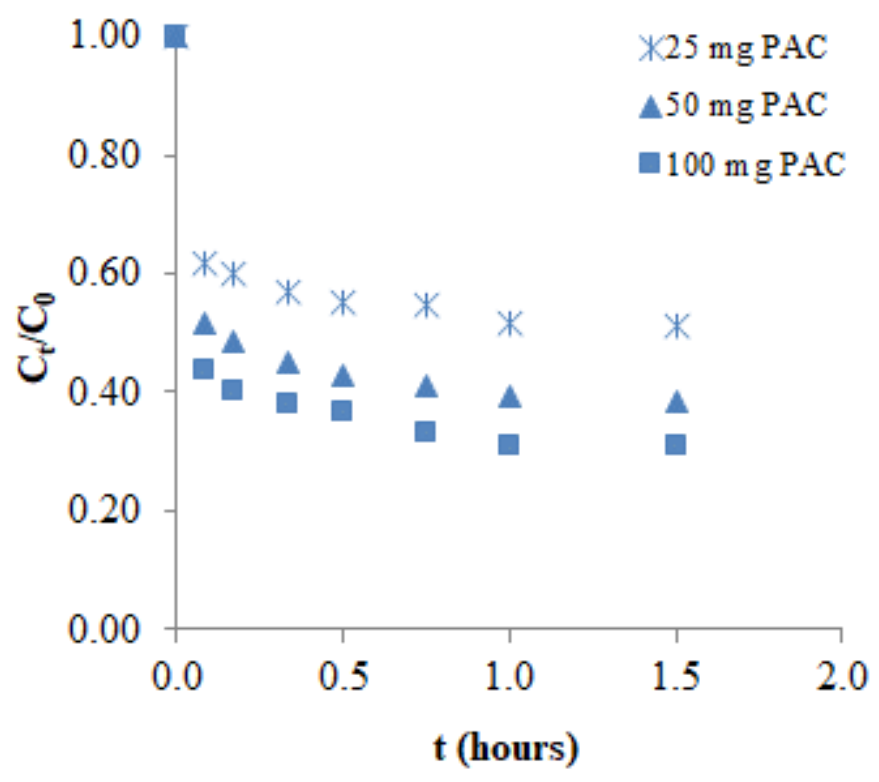

Figure 2: Effect of contact time on the adsorption of metamizole sodium (MS) on powder activated carbon (PAC).

Isotherm equations are used to model the interaction between the adsorbate and the adsorbent for the adsorption processes. Figure 3 and 4 are the Giles isotherms of MS on PAC at $37^{\circ} \mathrm{C}$ in SGF and SIF, respectively. The shapes of the isotherms in Figure 2 and 3 fit the L type in accordance with the Giles isotherm classification. $L$ type means there is a high affinity between PAC and MS (14). 


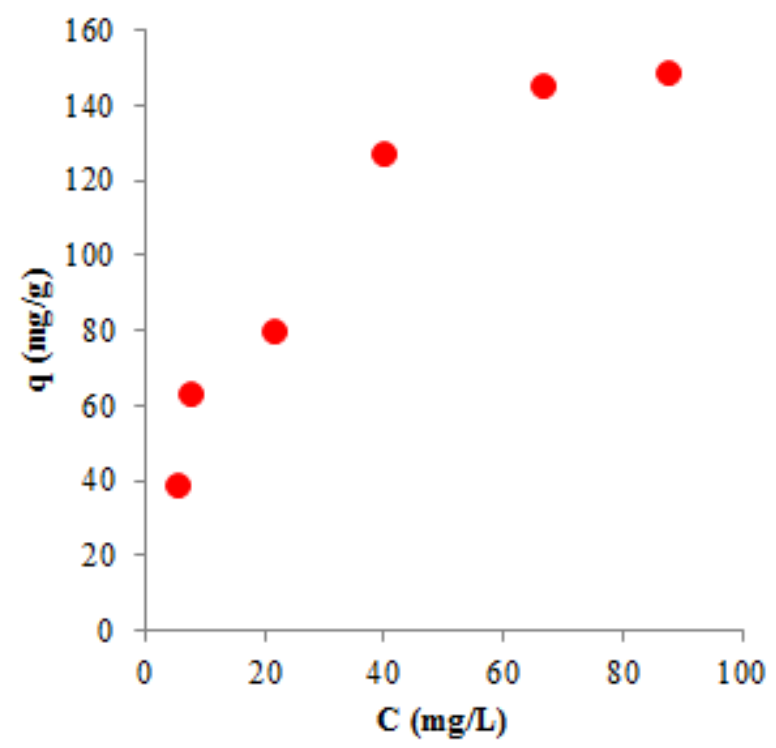

Figure 3: Giles isotherm for the adsorption of MS on PAC in SGF at $37^{\circ} \mathrm{C}$.

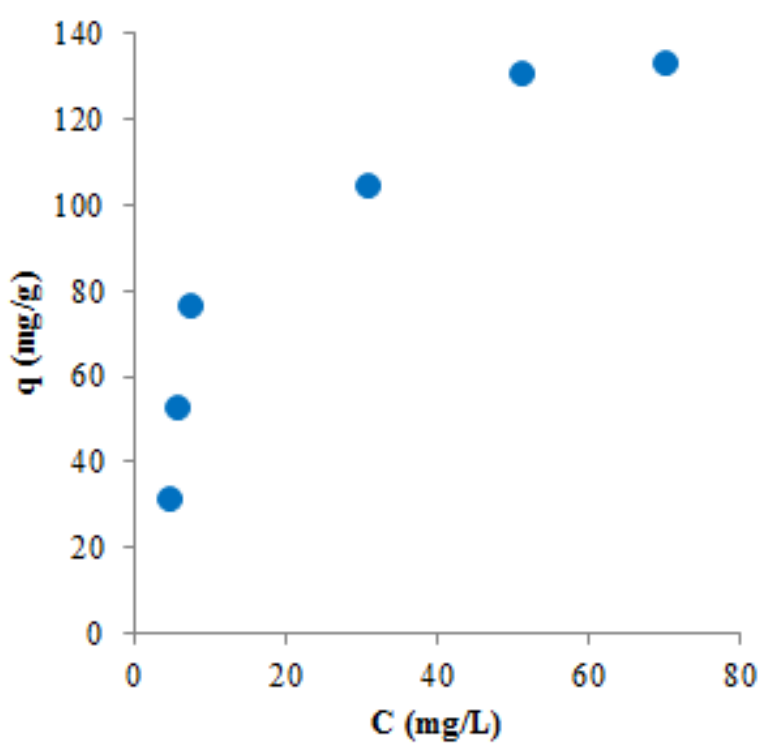

Figure 4: Giles isotherm for the adsorption of MS on PAC in SIF at $37^{\circ} \mathrm{C}$.

Data obtained from equilibrium experiments were modeled by using the Langmuir (Figures $5 \mathrm{a}$ and $6 a$ ) and the Freundlich (Figure $5 b$ and $6 b$ ) isotherm equations. Langmuir (15) and Freundlich (16) isotherm equations in their linear forms are respectively shown below.

$$
\begin{array}{r}
\frac{C}{q}=\frac{1}{Q b}+\frac{C}{Q} \\
\ln q=\ln k+n \ln C
\end{array}
$$

C shows the equilibrium concentration $(\mathrm{mg} / \mathrm{L})$; $\mathrm{q}$ shows the amount of adsorption at the equilibrium ( $\mathrm{mg} / \mathrm{g})$; $\mathrm{Q}$ shows the maximum adsorption capacity $(\mathrm{mg} / \mathrm{g}) ; \mathrm{b}$ is the adsorption equilibrium constant $(\mathrm{L} / \mathrm{mg}) ; \mathrm{k}$ and $\mathrm{n}$ are Freundlich constants. 
As seen in Table 1, the Langmuir model represents the adsorption of MS on PAC better than the Freundlich model. The Langmuir model indicates a localized adsorption with a monolayer coverage on the surface of the adsorbent where the adsorption heat is indepedent of the adsorbed amount of the material (17).

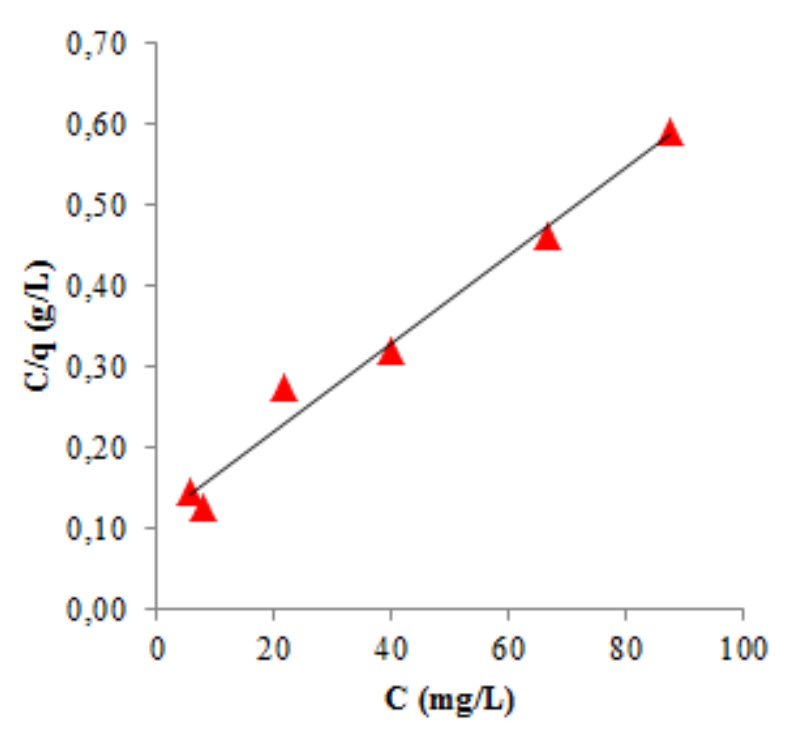

(a)

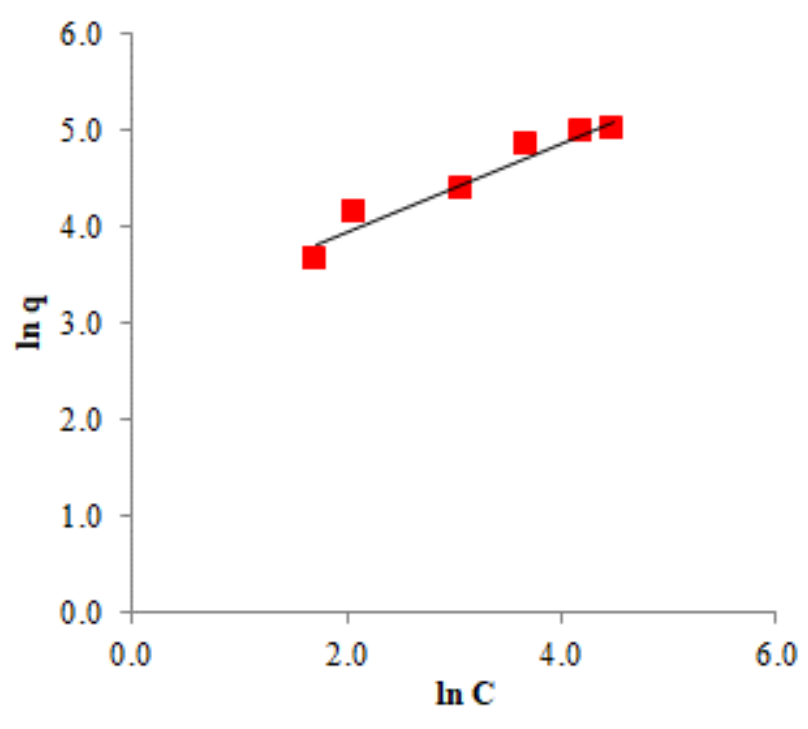

(b)

Figure 5: Langmuir and Freundlich isotherms for the adsorption of MS on PAC in SGF at $37^{\circ} \mathrm{C}$.

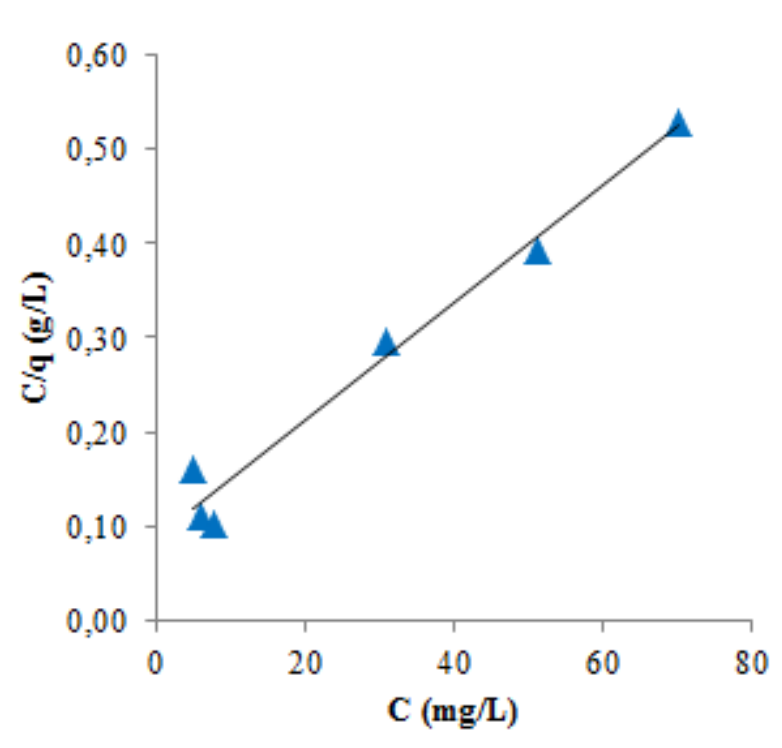

(a)

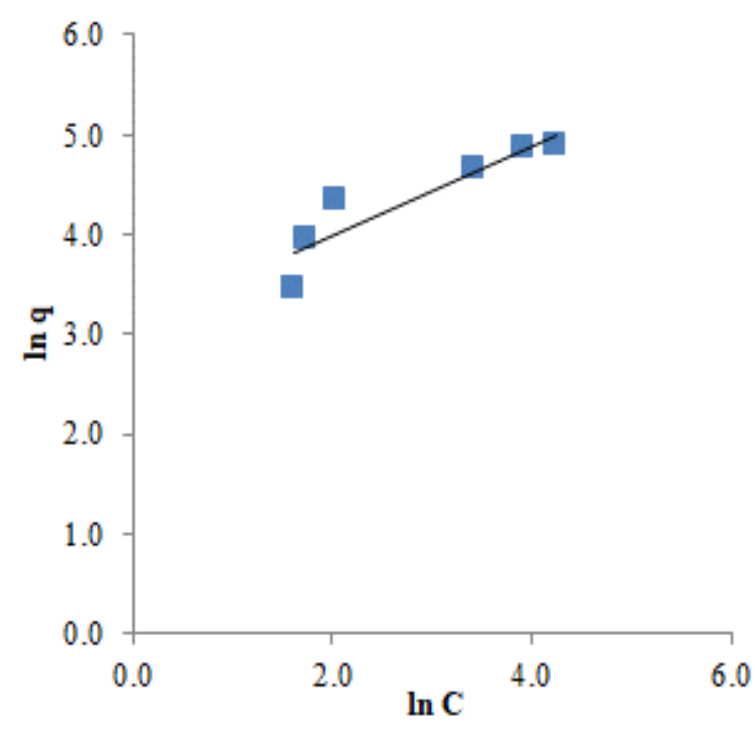

(b)

Figure 6: Langmuir and Freundlich isotherms for the adsorption of MS on PAC in SIF at $37^{\circ} \mathrm{C}$. 
Table 1: Isotherm parameters of the adsorption of MS PAC in SGF and SIF.

\begin{tabular}{ccccccc}
\hline & \multicolumn{3}{c}{ Langmuir model } & \multicolumn{3}{c}{ Freundlich model } \\
\cline { 2 - 7 } SGF & $\mathrm{Q}(\mathrm{mg} / \mathrm{g})$ & $\mathrm{b}(\mathrm{L} / \mathrm{g})$ & $\mathrm{R}^{2}$ & $\mathrm{n}$ & $\mathrm{k}$ & $\mathrm{R}^{2}$ \\
\cline { 2 - 7 } SIF & 185.19 & 0.05 & 0.981 & 0.47 & 20.16 & 0.945 \\
\hline
\end{tabular}

pKa (Ka: acidity constant) is an important parameter that controls the dissociation of adsorbate and effects the adsorption. This effect is closely related to the solution pH. MS (pKa $=-1.2$ ) exists its anionic form in the solution (18). Another parameter which importantly effects the adsorption is the surface charge of the adsorbent which is PAC in this study (4). PAC is an amphoteric material and has a point of zero charge $\left(\mathrm{pH}_{\mathrm{PzC}}\right)$ of 9.5 which means that the charge of the surface is positive at the working $\mathrm{pH}$ values, 1.2 and 7.5. But the net positive charge on the surface at the $\mathrm{pH} 7.5$ is lower than the one at the $\mathrm{pH} 1.2$ which is more closer to the pHpzc. The maximum adsorption capacity obtained at the $\mathrm{pH} 1.2$ (in SGF) is higher than the one obtained at the $\mathrm{pH} 7.5$ (in SIF). The adsorption capacity of PAC decreased with the increasing $\mathrm{pH}$ which shows the main role of electrostatic attraction on the adsorption of MS. The adsorption of MS occurs related to the electrostatic attraction forces between the anionic MS molecule and surface of PAC charged positively.

Dispersive (dispersion) and electrostatic interactions are the types of interactions which rule the adsorption of aromatic compounds on activated carbons. Dispersive interactions between the $\pi$-electrons of the aromatic rings of MS molecules and those of the graphene layers of PAC may be also contributive in this process $(5,19-23)$.

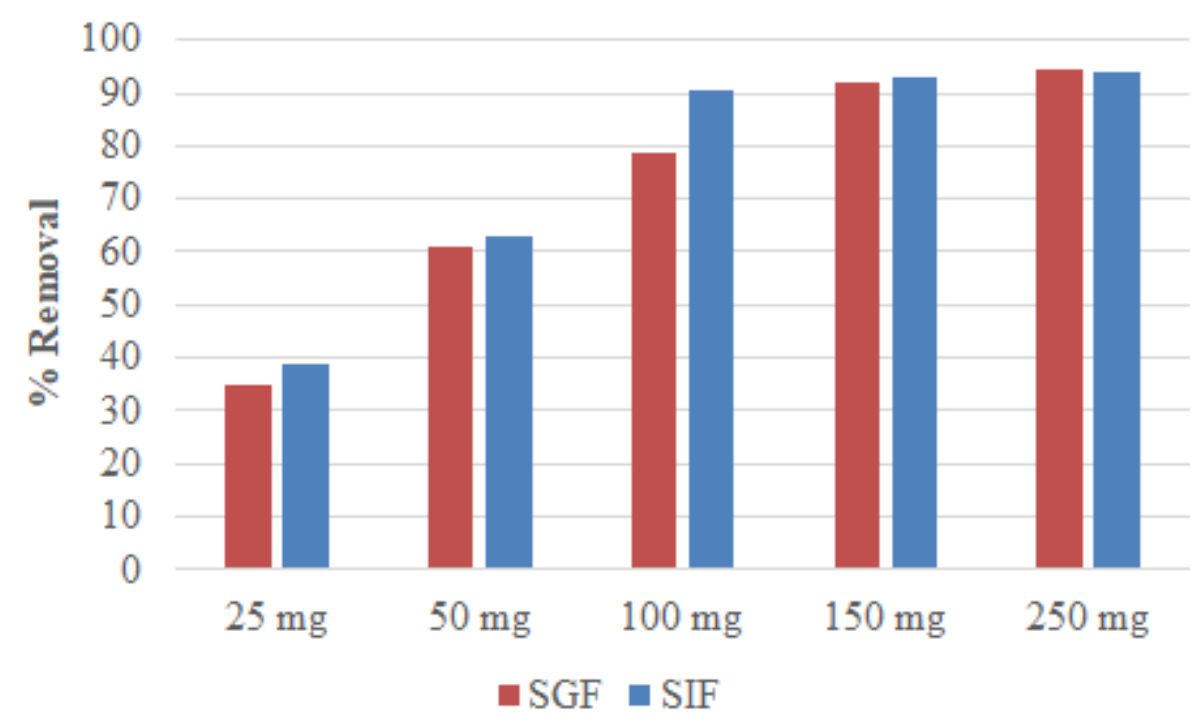

Figure 7: Comparison of \% Removal of MS (metamizole sodium) for different amounts of PAC (powder activated carbon). 
Figure 7 shows the effect of adsorbent amount on the removal of MS for various amounts of PAC. \% Removal increases with an increase in the amount of PAC and stays almost constant at the adsorbent amounts higher than $100 \mathrm{mg}$. PAC used showed a high removal capacity for MS.

\section{CONCLUSIONS}

Adsorption of MS (metamizole sodium) on PAC (powder activated carbon) was studied in simulated gastric and intestinal fluids at body temperature. The adsorption process achieved to the equilibrium in 1 hour, but more than eighty percent of the total adsorption occurred in the first 5 minutes. The maximum adsorption capacities of MS on PAC were calculated using the Langmuir isotherm model. The maximum adsorption capacity of MS in the simulated gastric fluid was found to be $185.19 \mathrm{mg} / \mathrm{g}$ which is higher than the one obtained in the simulated intestinal fluid found to be $161.29 \mathrm{mg} / \mathrm{g}$. The adsorption capacity increased with decreasing $\mathrm{pH}$. These results indicate the role of electrostatic attraction in this prosess. Electrostatic interactions played the main role for the adsorption of MS on PAC with a possible contribution of $\Pi-\Pi$ dispersion interactions. Taking into account the equilibrium time and the adsorption capacities of the PAC, it can be concluded from the above that the adsorption of MS on PAC is a fast process with a high removal efficiency. Results of the present study is important for the treatment of overdose or poisoning by preventing the further absorption of drug.

\section{REFERENCES}

1. Bentur Y, Cohen O. Dipyrone Overdose, Journal of Toxicology: Clinical Toxicology 2004; 42(3): 261265.

2. Bar-Oz B, Bulkowstein M, Benyamini L, Greenberg R, Soriano I, Zimmerman D, Bortnik O, Berkovitch M. Use of antibiotic and analgesic drugs during lactation. Drug safety. 2003 Nov 1;26(13):925-35.

3. Otero M, Grande CA, Rodrigues AE. Adsorption of salicylic acid onto polymeric adsorbents and activated charcoal, Reactive \& Functional Polymers 2004; 60: 203-213.

4. Çalışkan E, Göktürk S. Adsorption characteristics of sulfamethoxazole and metronidazole on activated carbon. Separation Science and Technology. 2010 Jan 29;45(2):244-55.

5. Çalışkan Salihi E, Aydın E. Adsorptive characteristics of isoniazid on powdered activated carbon: $\Pi-\Pi$ Dispersion interactions at the solid-solution interface. Journal of Dispersion Science and Technology. 2017 Apr 3;38(4):457-462.

6. Cantürk Talman RY, Çalışkan Salihi E, Göktürk S, Baştuğ AS. Removal of ethacridine lactate from aqueous solutions onto bentonite and activated carbon. Fresenius Environmental Bulletin. 2015; 24(11), 3603-3608.

7. Kyzas GZ, Lazaridis NK, Deliyanni EA. Oxidation time effect of activated carbons for drug adsorption. Chemical engineering journal. 2013 Dec 31;234:491-9. 
8. Kyzas GZ, Deliyanni EA. Modified activated carbons from potato peels as green environmental-friendly adsorbents for the treatment of pharmaceutical effluents. Chemical Engineering Research and Design. 2015 May 31;97:135-44.

9. Jain S, Vyas RK, Pandit P, Dalai AK. Adsorption of antiviral drug, acyclovir from aqueous solution on powdered activated charcoal: kinetics, equilibrium, and thermodynamic studies. Desalination and Water Treatment. 2014 Jul 29;52(25-27):4953-68.

10. Bajpai SK, Bhowmik M. Poly (acrylamide-co-itaconic acid) as a potential ion-exchange sorbent for effective removal of antibiotic drug-ciprofloxacin from aqueous solution. Journal of Macromolecular Science, Part A. 2010 Dec 29;48(2):108-18.

11. Guedidi H, Reinert L, Lévêque JM, Soneda Y, Bellakhal N, Duclaux L. The effects of the surface oxidation of activated carbon, the solution $\mathrm{pH}$ and the temperature on adsorption of ibuprofen. Carbon. 2013 Apr 30;54:432-43.

12. Baccar R, Sarrà M, Bouzid J, Feki M, Blánquez P. Removal of pharmaceutical compounds by activated carbon prepared from agricultural by-product. Chemical engineering journal. 2012 Nov 15;211:310-7.

13. Nabais JV, Mouquinho A, Galacho C, Carrott PJ, Carrott MR. In vitro adsorption study of fluoxetine in activated carbons and activated carbon fibres. Fuel Processing Technology. 2008; May 31;89(5):549-55.

14. Giles, CH, MacEwan, TH, Nakhwa, SN, Smith, DJ. Studies in adsorption. Part XI. A system of classification of solution adsorption isotherms, and its use in diagnosis of adsorption mechanisms and in measurement of specific surface areas of solids. Journal of the Chemical Society. 1960; 786: 39733993.

15. Langmuir I. The adsorption of gases on plane surfaces of glass, mica and platinum. Journal of the American Chemical society. 1918 Sep; 40(9): 1361-403.

16. Freundlich $\mathrm{H}$. Über die adsorption in Iösungen. Zeitschrift für physikalische Chemie. 1907 Oct $1 ; 57(1): 385-470$.

17. Myers, D. (1999) Surfaces, Interfaces, and Colloids: Principles and Applications; New York: John Wiley \& Sons, Inc.

18. Marra MC, Silva PL, Muñoz RA, Richter EM. Ultra-fast determination of scopolamine, orphenadrine, mepyramine, caffeine, dipyrone, and ascorbic acid by capillary electrophoresis with capacitively coupled contactless conductivity detection. Journal of the Brazilian Chemical Society. 2014 May;25(5):913-9.

19. Wu Y, Xi B, Hu G, Wang D, Li A, Zhang W, Lu L, Ding H. Adsorption of tetracycline and sulfonamide antibiotics on amorphous nano-carbon. Desalination and Water Treatment. 2016 Oct 7;57(47):22682-94.

20. Ji L, Chen W, Zheng S, Xu Z, Zhu D. Adsorption of sulfonamide antibiotics to multiwalled carbon nanotubes. Langmuir. 2009 Sep 3;25(19):11608-13.

21. Gao Y, Li Y, Zhang L, Huang H, Hu J, Shah SM, Su X. Adsorption and removal of tetracycline antibiotics from aqueous solution by graphene oxide. Journal of colloid and interface science. 2012 Feb $15 ; 368(1): 540-6$.

22. Wibowo N, Setyadhi L, Wibowo D, Setiawan J, Ismadji S. Adsorption of benzene and toluene from aqueous solutions onto activated carbon and its acid and heat treated forms: influence of surface chemistry on adsorption. Journal of Hazardous Materials. 2007 Jul 19;146(1):237-42.

23. Rivera-Utrilla J, Sánchez-Polo $M$. The role of dispersive and electrostatic interactions in the aqueous phase adsorption of naphthalenesulphonic acids on ozone-treated activated carbons. Carbon. 2002 Dec 31;40(14):2685-91. 
